\title{
A CUP SIGNED BY BRYGOS AT OXFORD.
}

\author{
[Plate IX.]
}

A CoMplete drawing is reproduced in Plate IX. of a kylix ${ }^{1}$ in the Ashmolean Museum, signed on the handle BPV^OS EГE々EN. Apart from the interest of its signature, the vase is important for its subject, which appears to be rare if not unique. I have, however, been unable to determine with certainty either subject or authorship, and shall content myself with trying to establish a sound basis for further investigation, and suggesting features of probable significance.

The kylix is large, with a comparatively small design in the interior. The chief measurements are: height, $12 \mathrm{~cm}$., diameter, $33 \mathrm{~cm}$., breadth across handles, $41 \mathrm{~cm}$., diameter of inner circle, $14 \mathrm{~cm}$. The cup is fragmentary, but the existing surface is well preserved, and the black, which is laid on rather thickly in parts, is deep and glossy throughout.

The interior scene has a border of stopped maeander in sets of 2,3 , or 4 broken alternately by chequer squares and saltire squares with dots at the ends of the cross-arms. The two scenes on the exterior have no border but a reserved red line above and below. There is a fragmentary palmette design beneath one handle.

The scene in the interior (Plate IX.) is practically complete except for a gap at the bottom of the circle, which, though it leaves the figures intact, possibly deprives us of some clue to the interpretation of the subject. All that is certain is that the two figures are kneeling on some level surface, the horizontal line of which marks off a reserved segment of the circle with depth equal to about a quarter of its diameter. The horizontal border of egg and tongue suggests, though it does not invariably denote, a definite part of the scene, such as an altar.

The attitudes of the figures are clearly and carefully worked out. The left-hand warrior has his back turned to us and looks out sharply to the left, drawing his sword from the sheath; his left knee is raised and bent, and the foot rests on the horizontal line. The right was apparently slightly bent at the knee, and in profile-to judge from the drawing of the muscles of knee

${ }^{1}$ Given by Mr. E. P. Warren of Lewes. I am indebted to the Keeper of the Ashmolean Museum for permission to publish the vase. A small photograph of the interior appeared in Oxford Ieports of the Unitersity Institutions, $00^{\circ}$ 


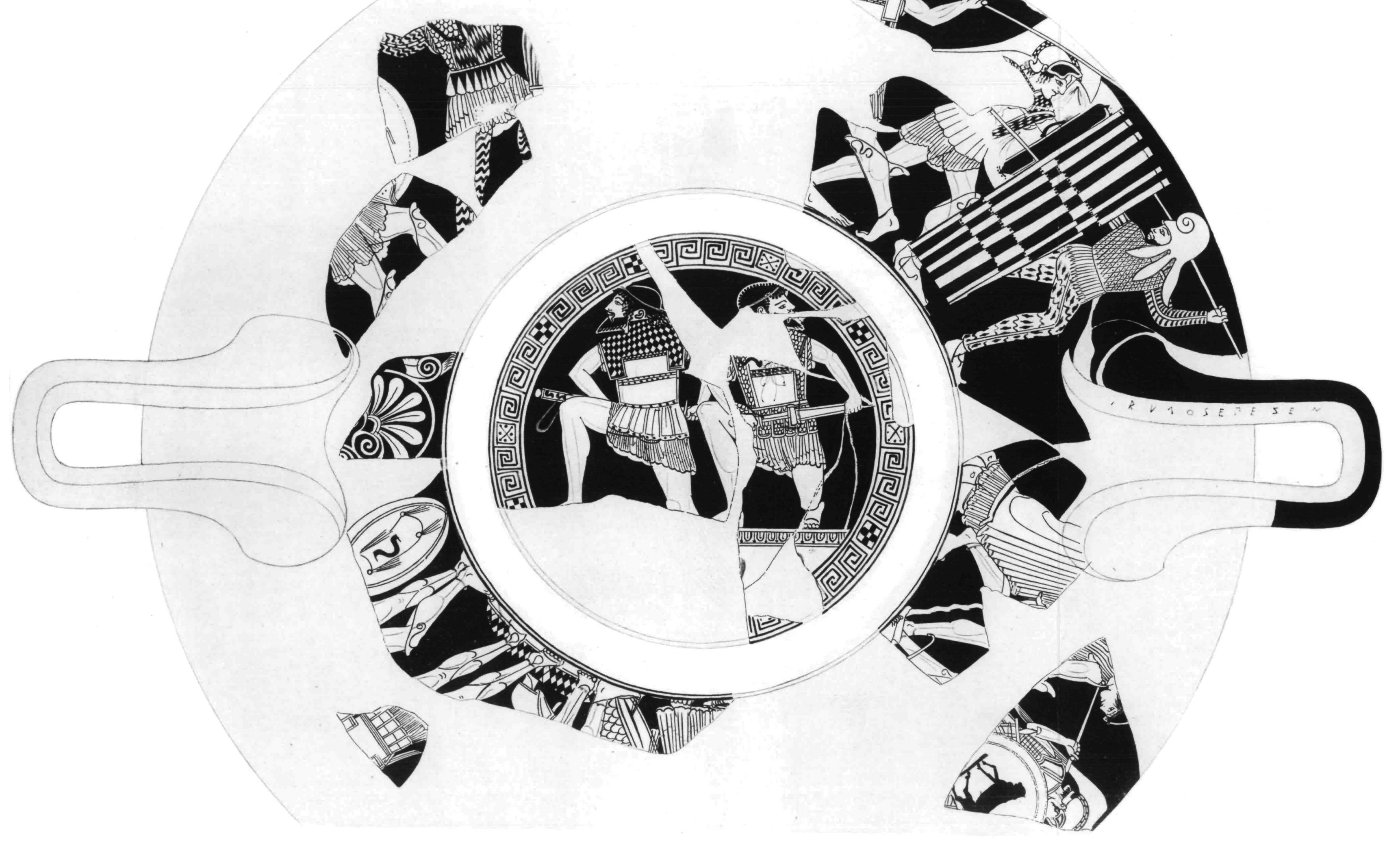


and upper leg; it would naturally fall behind him, i.e. in front of the horizontal line, but whether the weight rests on it or on some object at a lower level, is not clear from the fragmentary state of the drawing.

The position of the right-hand figure amounts practically to a reversed view of the other, except that here the right knee is raised (repeating the line of the other's left) and the left leg is drawn in bold foreshortening with the knee bent back, short of the level, and only half hiding the frontal foot, which continues in an almost vertical line to the ground. The foot rests on the toes- 5 small circles overarched by a black line convex to the knee, indicating the sharp bend at the toe-joints.

Both men are bareheaded but wear an elaborate cuirass over the chiton; both draw their swords turning their heads sharply in opposite directions.

Below the horizontal line, at the edge of the break, are two patches of dull brown colour.

The exterior (Plate IX.) is more fragmentary but also more capable of being recontructed from familiar types.

Side A, Arming: beginning at the signed handle, from left to right. Fragments $a, b, c$. Group of old man leaning on stick and youth putting on his greaves. The rise of the handle-curve on the left of $(a)$ indicates the position of the fragment; the knotted stick connects it with fragment $(c)$, and the attitude of the stooping youth ${ }^{2}$ on the two fragments determines the position of $(b)$ with greave held ready to put on. At the right of frag. (c) are two profile feet (to 1.) overlapping considerably. The right and foremost is preserved up to the knee, with a greave: of the left only the beginning of the greave line (relief) is visible, along the edge of the break. A bow, apparently with no string to it, lies horizontally across the feet of this figure. Above, on the right of frag. $(b)$ is the frontal body (to the waist) of an armed warrior whose head is turned to the right, i.e. in the opposite direction to that of his feet. With his raised right he holds a spear slantwise over his shoulder; a shield (emblem: bull) hangs on his left arm, and a sword at his side; the crest of his helmet has a long tail-piece hanging down on the left as far as his belt. Projecting into the round of his shield is an angle of drapery, which probably belongs to a figure of the next group.

Fragments $d c$ form a larger group or series of which the upper half is mostly broken away. Two profile feet (to $r$.) are the only indication of a figure on the left. The other figures are, from l. to r.: a woman in a long chiton, frontal, with a shield apparently leaning up against her side; 3 the warrior to whom it belongs stands next with 1. foot frontal, wearing greaves. Behind his feet and those of the next figure is one of those small, carefully executed studies of armour for which Brygos and Douris seem to

\footnotetext{
${ }^{2}$ Cp. similar figures, on Douris' Vienna cup, Furtw.-Reichhold, liii. (A), and on the Brygan piece, Gerhard, Auserlosene Vasenbilder, 269-70 (Vatican).

3 Cp. Fairbanks, White Athenian Lckythoi,
}

p. 157, Fig. 39, where a shield leans against the warrior's mantle; against his knee on a Aúkos hydria, Boston (9667 Coolidge) ; against his spear on a lekythos in Oxford. Cp. F. R. liii. et clia. 
have had a partiality : ${ }^{4}$ a shield lying on the ground and a helmet standing on top of it. The first shield is covered on the convex side with a scale pattern, the second with a chequer pattern-both of which we found conspicuous in the armour of the warriors on $I$. The remaining two figures on frag. (d) are drawn from behind and with no incompetent handling of the problems involved. The positions of the feet clearly suggest the uneven distribution of weight in an easy standing posture; the left-hand figure stands on tiptoe. On the right of the last figure is a shield seen mainly on the inside, in three-quarter view. We have still to mention a fragment $(e)$ with the back of a warrior wearing corslet, and the end of a helmet-crest

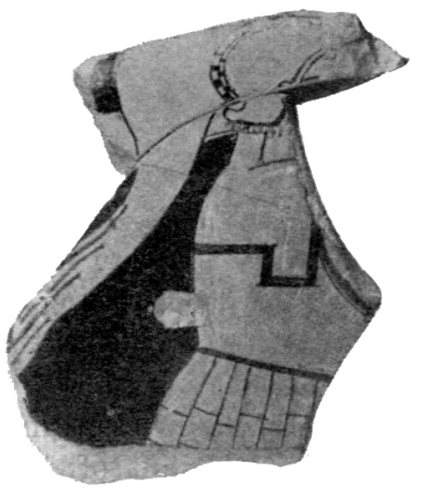

FIG. 1.-FragMeNT $h$. showing on the left, which fits in well enough above the first of these two figures.

Under the handle (frag. $f$ ) palmette and scroll design interrupted by the foot of a running figure belonging to the first group on $B$.

$B$. Frag. $g$ shows the rise of the handle on the left.

The fragments $g, i$, together with $h$ (which I venture to place here though it is not included in the actual restoration of the vase) form the first group in a Battle between Greeks and Persians. A Greek rushes forward from the left, holding out a shield, his right arm apparently raised from the sboulder to strike. On $h$ (Fig. 1) the helmet with long crest and the neat linear drawing of the corslet are stylistically of a piece with the rest of the kylix; and allowing for the loss of a small wedge-shaped flake between the fragments, the curve of the surface no less than the attitude of the figure formed a continuous whole. The curious projection behind the helmet is probably a broad sabre flourished over the left shoulder, after the fashion of the vase, Hartwig, Meisterschalen lvi (Edinburgh) and many other examples. So far as I can judge there seems to be no valid technical ground why the fragment should not be inserted here.

On (i)-which should be placed rather nearer to $(g)$-we have part of the Greek's shield, and then immediately the frontal body of a Persian moving to the $r$. with right arm raised. Part of his decorated leggings appear on the edge of frag. $(g)$. On his right is the sleeved arm of a second Persian grasping a sword hilt.

At this point we come to a large gap of about one-third the length of the side: the remaining third together with the signed handle consists

'Cp. 'Contest for Aıms,' cylix in B.M., E 69 (Bild $\imath$. Liei, p. 213, redrawn Hartwig, Meisterschalen, p. 359), and Gerhard, $A$. $V$. Pll. 269-70; also Luynes, Fases Peints, Pl.
XII.; the motive occurs five times in Douris' Vienna eup (F.-R. liv.), twice with the shield on end. 
of a large fragment $(k)$, and a small one above it $(j)$, which are obviously contiguous.

On the extreme left of this group is a Greek (drawn in three-quarter back view), who rushes at an opponent on his left with levelled spear. He strides over the outstretched $r$. foot of a wounded man, who probably lay half prostrate, filling the gap between the Persians on the left and the Greeks on the right. ${ }^{5}$

There remains the most interesting group on the exterior of the kylix : a Greek and a Persian in single combat. The figures are strongly contrasted, no less in attitude than in arms and accoutrements. The head of the Persian, with striking profile and wearing a Phrygian cap, is one of the few preserved on the exterior. But the most singular feature is his great oblong wicker shield, which is so far the only known parallel to the one illustrated in Jahrbuch 1911, p. 281 (Schröder: $Z u$ Mikons Gemälden der Marathonschlacht in der Stoa Poikile).

A few notes as regards the technique.

The drawing is mainly in thick black relief with a sparing use of colour: the face profile, eye, ear, and nostril, the upper edges and lower strokes of the beard, the main lines of armour and drapery, the markings of greaves, generally the ornaments of the shield, the ankle and the marks at the back of the knee $\smile$ are in black relief.

The ends of the hair thin off into dark brown glaze; the minor lines of drapery, the inner markings of the body, and once the interior of a shield, are in brown. We sometimes find the brown musculature in the leg side by side with the black greave-markings.

Red paint is used for the circlets of the two warriors in the interior, and for the strings which tie their shoulderpieces in front.

The hair contour is reserved; in one case the hair has a single line of raised dots on its outer edge, a double row against the face, making a sharp angle at the temples.

The subject of the interior scene $(I)$ presents an attractive problem. The two warriors fall into none of the regular types or classes of vaseinteriors. They are drawn with a scrupulous care for the disposition of their limbs and an eye for significance of attitude; they appear to be the expression of a very definite idea in the mind of the painter.

The interpretation really turns on the meaning we attach to the reserved segment and the line which cuts it off. One is tempted at first sight to assume that it is the top of a wall or fortification on which the two warriors kneel in an attitude of suspicious and watchful defence. Yet we have abundant examples of the use of a reserved segment simply for convenience in the design. Frequently there is a horizontal border of egg-and-tongue pattern. In certain cases it is not clear whether or no the line has a bearing on the scene. On a white cup in the British Museum

` For the figure cp. Berlin Gigantomachy, type among the 'Melian' reliefs in the Terra. Gerhard, Trinkschalen, x.-xi., and F. -R. xxv. cotta Room of the British Museum. Ilioupersis, etc. It is interesting to find the 
(D1) the feet of the bull carrying Europa rest on this line. On another fragmentary white vase (Benndorf, Griech. u. Sicil. Vasenbilder, PI. XI. 2), where Herakles fights with an Amazon, the sole of the Amazon's extended foot projects downwards across the line.

On a kylix at Leyden, on the other hand (Roulez, Vases Peints, p. 1, Pl. II.), a segment marked off by a line, with egg-and-tongue border beneath it, clearly represents either an altar, on which the goddess Athena stands, or the basis of her image. It is worth noticing that neither the goddess nor her votary stands actually on the line, but their feet and legs are cut off by it some way below the knee. On the exterior is a very similar group, showing the two ends of the structure-a slab projecting over low perpendicular sides-and at the left a votary standing on the groundline and stooping

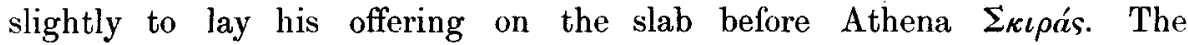
possibility of an altar is all the more to be considered as it gives the most plausible explanation of the two brown daubs. Also, the egg-and-tongue border is a very common feature of altars on vases.

Nevertheless the assumption by Mr. Beazley (J.H.S. 1910, p. 65), that the scene is practically a reproduction of a Kleophradean subject-'.two warriors fighting at an altar'-seems to me premature in the face of (1) so vital a discrepancy as that which he admits, i.e. that they are in one case opponents, and in the other allies ${ }^{6}$; and (2) the stronger a priori probability, deduced as it is from the figures themselves. The men appear to have just clambered on to a wall (possibly we are to see the rounded ends of laddershafts in the problematic daubs aforesaid) and crouch in attitudes half aggressive and half defensive, as men would in a position at once so commanding and so exposed. In bold mood one surmises a scene from the Persian War; in keeping with the subject of $B$ on the exterior. As the Greek attack on the Persian camp after Plataea it would be, in contemporary vase-painting, a unique expression of the patriotic vein. But according to Herodotus (ix. 67-70) the Tegeans and not the Athenians were the first to scale the walls of the Persian camp,-an incident which an Athenian potter would not be anxious to immortalise. Moreover two men with bare heads, and no shields, looking out in opposite directions with swords halfdrawn, do not suggest the sudden storming of a stronghold after battle so much as some stealthier form of aggression or even watchful defence.

We fall back on a subject familiar in Greek art, the expedition of Odysseus and Diomede to carry off the Trojan Palladium. True there is no palladium in the drawing nor any hint of its relevance to the scene; nor is there any representation of the subject perfectly analogous to this. The nearest parallel perhaps is a black-figure scene on an aniphora, Arch. Zeit. 1848, Pl. 17. 2, where two warriors kneel side by side, in full arnour, holding spears, and their heads are turned in opposite directions.

\footnotetext{
${ }^{6}$ Even if we suppose them to be at bay on the altar, the absence of any assailant would make the effect absurdly flat (contrasted, say, here is far too purposeful and comprehensive to be a mere excerpt from a completer scene.
} 
Our painter, following the tradition, has been at some pains to distinguish the two heroes by many small traits (e.g. hair, sheaths, corslets, etc.); he has decided for himself how much it would be practical for night-raiders to carry in the way of arms and impedimenta. The result is a certain directness and vitality in the conception, reminding one of the famous Sosias vase in Berlin (F.-R. cxxiii.) and more remotely of the Penthesilea motive conceived at its greatest moment for the first time in the Munich cup.

We have still to take up the challenge of the signature. It must be allowed in the first place that the work of the painter is not necessarily confined to pieces signed by him-still less to those with the Firm-mark of the potter; and conversely that the potter's signature does not imply the work of one painter only.

In the Wiener Vorlegebläter are published $(C$ Pl. 7, $2 a-l)$ the frag-

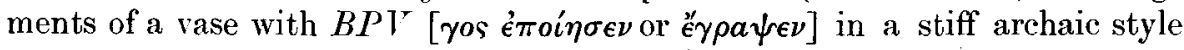
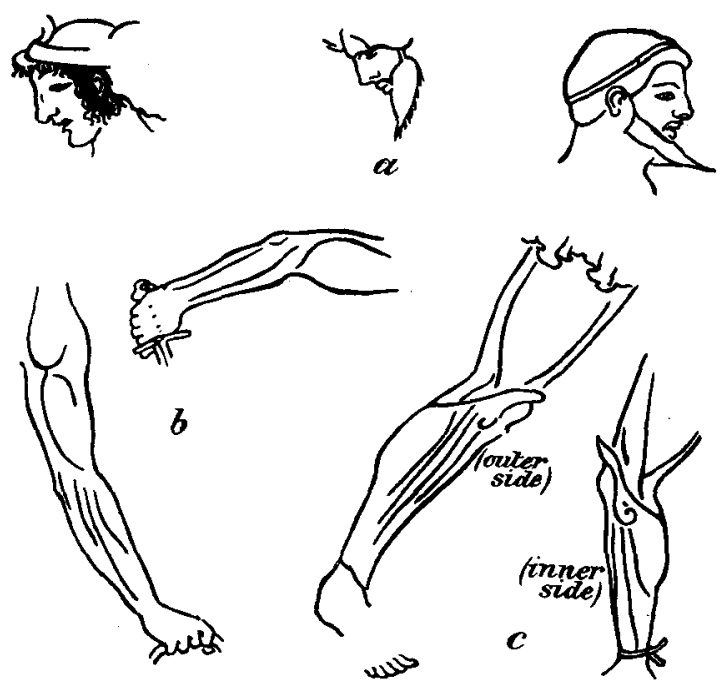

Fig. 2 .

totally unlike that of the great Ilioupersis (Louvre) and Iris (B.M.) Boúros

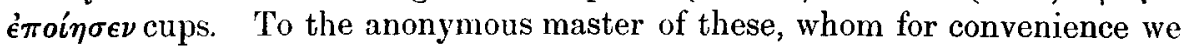
call Brygos, Hartwig, following others, assigns a great quantity of work ranging in type and quality from the most advanced to the most primitive of the eight signed pieces in his list.

It is hard to believe the Frankfurt kylix (best reproduction Mon. d. Inst. 1850 tav. G.) to be even an early work by the same hand; it is however to this that our cup bears, superficially, at least, a decided resemblance, while it differs from the maturer work in several characteristic and peculiar details.

In the style we associate with Brygos the nostril is rendered as in $(a)$ in Fig. 2; the muscles of the leg (inner or outer side indiscriminately), and the muscles of the upper leg as in $(c)$; the muscles of the arm, as in $(b)$. In 
the Oxford cup the nostril is thicker and blacker, of a different shape and differently placed. The muscles of the inner and outer sides of the leg are regularly distinguished; in the lower arm there is a curious short stroke joining the ends of two parallel lines running down the arm. As we saw, the use of colour is very sparing, in contrast to the lively colouring of Brygan designs.

The features (with the notable exception of the long narrow Brygan eye) appear to be blunter, yet without the engaging sauciness of the Brygan snubnose, and we miss his fine spirited limb-contour. The scheme of the interior (roughly, two uprights on a horizontal line) is as unlike the proper Brygan schemes as is the pseudo-Brygan piece (Murray, Vase Designs in the British Museum, No. 48).

In the border, the saltire squares with dots at the ends of the cross strike one as un-Brygan; but they occur in the Frankfurt vase (above), which has further in common with ours a certain stiff serial arrangement of the figures on one side of the exterior, and a liberal use of scale and chequer patterns for armour. The third figure on the left on the 'Triptolemus' side, a man standing with head to r., body frontal, and feet to l., is a curious analogy to the fragmentary figure of a warrior in the first group of the Arming Scene.

In both-as contrasted with the Würzburg $\kappa \hat{\omega} \mu o s$ (F.-R. 50)-the outer line of the reserved hair-contour is smooth and does not follow the undulating line of the hair.

A broken kylix in the British Museum (E 73), assigned by Hauser and Beazley to Kleophrades, has an original presentation of the Peleus and Thetis motive in the centre, surrounded by a zone with Nereus and seanymphs, with similar blackness of line; three feet on one side $(B)$ are drawn in foreshortening, one leg from behind with black knee-marks $\smile$; the leg of a kneeling figure has the muscles marked as in $e$; and in the lower part of Nereus' arm the two almost parallel brown lines are apparently joined by a short stroke at the top exactly as in the Oxford interior. The blunt drawing of nose and lips, the drawing of the ear, the occurrence of scale pattern in the interior are further points in common. The drapery edge however and the pattern of the border (with alternate chequer-squares) are totally different, and belong rather to Douris' style. This coincidence of certain details is significant in view of the correspondence (pointed out by Mr. Beazley; J.H.S. 1910 , p. 64) of our vase with another Kleophradean piece, as yet unpublished, in Athens.

Quite apart from the somewhat doubtful connexion of the interiors, discussed above, there is a striking resemblance between two scenes from the exterior representing arming. . The figures in both are nearly all seen from behind and the foreshortenings of the feet are the same.' Mr. Beazley concludes from the partiality of Kleophrades for back-views and foreshortenings that he, rather than Brygos, was the inventor of this scene.

Again, in the famous Ilioupersis hydria of Kleophrades, the figure to the right of the fallen man, a young warrior (attacked by a woman with a pestle, not as Furtwängler says as he is in the act of spoiling the corpse, but as he 
falls on one knee, already wounded, as the broken eye indicates) strongly recalls the attitude of the right-hand of our two warriors. ${ }^{7}$ The kneeling figure with one leg frontal and foreshortened is by no means a common one in severe Red-figure, although, just as in Kleophrades, we do find several examples of it. The use of the figure here is perhaps too deliberate and independent to be accounted for merely by 'transforence of type' (cp. Zahn, Ath. Mitth. 1898, p. $61 \mathrm{n}$.) but may nevertheless have been suggested by the Kleophradean motive. Nowhere else in Brygan work is the influence of Kleophrades so apparent, and it is partly for this reason that I am inclined to separate the Oxford vase from the main group of Brygos' pieces; partly also on the ground that the divergences from the usual forms are hardly attributable to a variation of manner, and certainly not to rapid or sketchy performance, of which we have, in the Maenads and Silens (Hart. Cab. des Méd., MS. xxxii,) an example far more in Brygos' temper. Compared with the Frankfurt vase it is too able and masterly to be accounted for, with that, as an early work; and should probably be assigned to some advanced member of his school, to whom also we might perhaps attribute the Frankfurt vase as a youthful piece.

M. A. B. Herford.

7 I know of no other figure where the knee, as here, does not rest on the ground, and the frontal foot continues the line of the upper leg downwards. Possibly it is an attempt to draw a squatting figure with the lower leg bent sharply back at the knee, and supporting the upper leg and thigh. The loop-shaped inner marking would then indicate the bulging muscle of such an attitude. 